\title{
Parallel Antagonism of Synaptic Transmission and Kainate/Quisqualate Responses in the Hippocampus by Piperazine-2,3-Dicarboxylic Acid Analogs
}

\author{
A. H. Ganong, ${ }^{*, 1}$ A. W. Jones, $\dagger$ J. C. Watkins, $\dagger$ and C. W. Cotman* \\ *Department of Psychobiology, University of California, Irvine, California 92717, and †Department of Pharmacology, \\ The Medical School, University of Bristol, Bristol BS8 1TD, England
}

A new series of potent antagonists of excitatory neurotransmission in the rat hippocampus has been identified. These derivatives of piperazine-2,3-dicarboxylate (PzDA) include the most potent acidic amino acid antagonists yet described for Schaffer collateral-commissural EPSPs. These antagonists also effectively block excitatory synaptic responses recorded in the lateral and medial perforant pathways and in the mossy fiber pathway.

The PzDA derivatives also block focal depolarizations produced by kainate, quisqualate, and $N$-methyl-D-aspartate. $N$-methyl-D-aspartate responses are more susceptible to inhibition by PzDA derivatives, although the spectrum of antagonism of $N$-methyl-D-aspartate and synaptic responses by PzDA derivatives is not parallel. However, the antagonism of kainate and quisqualate responses by PzDA derivatives shows the same rank order of potency as synaptic responses. These data indicate that synaptic receptors in the hippocampus have a pharmacologic profile similar to that of kainate or quisqualate receptors.

A great deal of evidence suggests that most excitatory CNS synapses use L-glutamate or L-aspartate as a transmitter (Fagg and Foster, 1983; Fonnum, 1984). The postsynaptic receptors mediating responses to L-glutamate and other amino acid excitants have been differentiated on the basis of their sensitivity to different agonists. Thus, the major excitatory amino acid receptors have been classified as those selectively activated by $\mathrm{N}$-methyl-D-aspartate (NMDA), kainate, or quisqualate (Davies et al., 1982; McLennan, 1983; Watkins and Evans, 1981). Excitatory amino acid receptors of the three major classes are present in discrete afferent fields throughout the CNS, although the role of many of these receptors in excitatory neurotransmission is not clear (Fagg and Foster, 1983; Fonnum, 1984; Watkins and Evans, 1981; Monaghan and Cotman, 1985).

A specific synaptic function of NMDA receptors has been demonstrated in the spinal cord and cortex through the use of selective antagonists for this receptor class (Davies and Watkins, 1982, 1983; Evans et al., 1979, 1982; Thompson et al., 1985). Extracellular recordings of other CNS excitatory pathways indicate that many monosynaptic responses are not susceptible to inhibition by specific NMDA antagonists, and, therefore, are mediated by a non-NMDA receptor type.

Precise pharmacological comparisons of synaptic and kainate or quisqualate receptors have not been possible because of the paucity of antagonists for these receptors (Foster and Fagg, 1984;

Received Sept. 24, 1984; revised June 27, 1985; accepted Sept. 25, 1985.

This work was supported by DAMD 17-83-C-3189 and the Medical Research Council, U.K.

Correspondence should be addressed to C. W. Cotman.

${ }^{1}$ Present address: Division of Neurosciences, Beckman Research Institute of the City of Hope, 1450 E. Duarte Road, Duarte, CA 91010.

Copyright (C) 1986 Society for Neuroscience 0270-6474/86/040930-08\$02.00/0
McLennan, 1983; Watkins and Evans, 1981). However, several derivatives of piperazine-2,3-dicarboxylate have recently been shown to be antagonists of monosynaptic afferent stimulation and kainate and quisqualate responses in several vertebrate spinal cord preparations (Davies et al., 1984). We have tested these new antagonists with respect to antagonism of excitatory synaptic transmission and amino acid excitant responses in the rat hippocampus. Some of these data have been presented in $\mathrm{ab}-$ stract form (Ganong et al., 1984).

\section{Materials and Methods}

\section{Preparation of slices}

Hippocampal slices were obtained from 45-60 d male Sprague-Dawley rats as described previously (Koerner and Cotman, 1982; White et al., 1979). Following dissection and cutting, $450 \mu \mathrm{m}$ slices were maintained in a static fluid bath containing experimental medium $(124 \mathrm{mM} \mathrm{NaCl}$, $3.3 \mathrm{~mm} \mathrm{KCl}, 1.2 \mathrm{mM} \mathrm{KH}_{2} \mathrm{PO}_{4}, 26.4 \mathrm{mM} \mathrm{NaHCO}, 2.5 \mathrm{mM} \mathrm{CaCl}_{2}, 2.4$ $\mathrm{mm} \mathrm{MgSO}$, and $10 \mathrm{~mm}$ D-glucose) at $32-34^{\circ} \mathrm{C}$ with their upper surfaces exposed to a warm, humid $95 \% \mathrm{O}_{2} / 5 \% \mathrm{CO}_{2}$ atmosphere. Following an equilibration period of $1-1.5 \mathrm{hr}$, slices were transferred one at a time to a recording chamber (Koerner and Cotman, 1983) modified for continuous superfusion of medium. Slices were secured in the recording chamber with an upper net and submerged in continuously flowing (0.5$1 \mathrm{ml} / \mathrm{min}$ ) medium. Antagonist solutions were applied by switching the superfusion fluid from control medium to medium containing specific concentrations of antagonist compounds.

\section{Synaptic responses}

Synaptic responses were elicited by electrical stimulation at $0.1 \mathrm{~Hz}$ from a twisted pair of $25 \mu \mathrm{m}$ stainless steel wires. Stimulus intensity was adjusted to elicit synaptic field potentials just below threshold for eliciting a population spike. The stimulating electrode was placed in different regions for stimulating Schaffer collateral-commissural, mossy fiber, lateral perforant, or the medial perforant pathway (Lanthorn and Cotman, 1981; White et al., 1979). Extracellular synaptic field potentials were recorded with a 4-10 $\mathrm{M} \Omega$ glass micropipette placed in the appropriate synaptic field.

Stimulating electrode placement was especially critical for mossy fiber responses; the stimulating electrode was placed just on the hilar side of the granule cell layer in the dentate gyrus. Field potentials in several locations along the CA3 pyramidal cell apical dendrites were examined for a given stimulating electrode placement. Mossy fiber responses were used only with a stimulating electrode placement that produced a prominent negativity in, but not distal to, stratum lucidum.

Lateral perforant path responses were obtained by positioning the stimulating and recording electrodes in the outer molecular layer of the dentate gyrus so as to record a response that exhibited potentiation in response to paired stimulation at 60 and $360 \mathrm{msec}$ interstimulus intervals. Medial perforant path responses were obtained by placing the stimulating and recording electrodes in the middle molecular layer of the dentate gyrus so as to record a response that exhibited depression in response to paired stimulation at 60 and $360 \mathrm{msec}$ interstimulus intervals (McNaughton, 1980). Schaffer collateral-commissural syn- 
aptic field potentials were obtained by positioning the stimulating and recording electrodes in CAl stratum radiatum.

\section{Intracellular recordings}

Intracellular recordings were from CA1 pyramidal neurons using $4 \mathrm{M}$ potassium acetate electrodes with DC resistances of 40-80 M 2 . A WPI M701 electrometer was equipped with a bridge circuit for passing current through the recording electrode. Recordings were from slices bathed in $10 \mu \mathrm{M}$ picrotoxin-containing medium to depress the large inhibitory potentials recorded intracellularly in these neurons. Concentrations of $\mathrm{Mg}^{2+}$ and $\mathrm{Ca}^{2+}$ were raised to 4-6 mM in slices exposed to picrotoxin to suppress epileptiform activity induced by blocking inhibitory responses (Brown and Johnston, 1983). Intracellular recordings were from neurons with resting potentials of at least $-55 \mathrm{mV}$, input resistances of greater than $20 \mathrm{M} \Omega$, and action potential amplitudes greater than 80 $\mathrm{mV}$.

\section{Excitant amino acid responses}

Extracellular focal potentials (Flatman and Lambert, 1979; Ganong and Cotman, 1982; Lanthorn and Cotman, 1983) induced by iontophoretic application of excitatory amino acids were recorded with a glass micropipette placed within about $100 \mu \mathrm{m}$ of the iontophoretic pipette in stratum radiatum of field CA1. The relative position of the recording and iontophoretic electrodes was adjusted following the initial placement to maximize the slope and amplitude of the focal potential produced by a brief iontophoretic application of an excitatory compound. Excitatory compounds were applied with 10-100 nA negative iontophoretic current pulses of $2-5 \mathrm{sec}$ adjusted to elicit focal potentials of 1-3 mV maximum amplitude. Backing currents up to $10 \mathrm{nA}$ were used when necessary. Responses to iontophoretically applied excitatory compounds were measured from a continuous $D C$. record on a chart recorder. Current pulses were applied $1 \mathrm{~min}$ apart to barrels of the iontophoretic pipette containing quisqualate, kainate, and NMDA, and there was a 2 min interval before the next successive applications of the agonists in that order. Excitant amino acid responses were recorded in the presence of $1 \mu \mathrm{M}$ TTX. Antagonists were applied by switching the control medium in which the slice was submerged to antagonist solutions.

\section{Compounds}

Solutions of $20 \mathrm{~mm}$ quisqualate (Sigma), kainate (Sigma), and NMDA (Tocris Chemicals, Essex) were dissolved in $20 \mathrm{~mm} \mathrm{NaCl}$ and adjusted to $\mathrm{pH} 7-8$ with $\mathrm{NaOH}$. Picrotoxin, TTX, and L-glutamate were obtained from Sigma. D,L-2-Amino-7-phosphonoheptanoate, the D- and L-isomers of 2-amino-5-phosphonopentanoate, and cis-2,3-piperidine dicarboxylate were obtained from Tocris. Piperazinc-2,3-dicarboxylatc (PzDA) derivatives were synthesized in the laboratory of J. C. Watkins, Bristol. The structures of these derivatives are shown in Figure 1.

\section{Results}

\section{Antagonism of Schaffer responses by $P z D A$ derivatives}

Dcrivatives of PzDA applied as $10-1000 \mu \mathrm{M}$ solutions were tested as antagonists of Schaffer collateral-commissural synaptic responses. Synaptic field potentials recorded from submerged slices were rapidly and reversibly depressed in a dose-dependent fashion by solutions of these derivatives (Fig. 2). The antagonism of Schaffer field potentials by PzDA analogs is summarized in Figure 3.

There were significant differences in the abilities of various PzDA derivatives to depress Schaffer responses. Piperazine-2,3dicarboxylate was a relatively poor antagonist of the Schaffer response; PzDA inhibited this response by $10 \pm 4 \%$ at $1000 \mu \mathrm{M}$ (mean $\pm \mathrm{SEM}, n=4)$. The $N$-benzoyl derivative of PzDA (BPzDA) was more effective than PzDA as a synaptic antagonist. Application of $1000 \mu \mathrm{M}$ B-PzDA inhibited Schaffer field potentials by $69 \pm 3 \%(n=4)$, and $200 \mu \mathrm{M}$ B-PzDA inhibited Schaffer responses by $34 \pm 2 \%(n=4)$. Several chlorobenzoyl PzDA derivatives were also tested: $N$ - $(m$-chlorobenzoyl)piperazine2,3-dicarboxylate ( $m$ CB-PzDA) and $N$-( $o$-chlorobenzoyl)piperazine-2,3-dicarboxylate (oCB-PzDA) were less potent than B-PzDA (Fig. 3).
General Structure<smiles>[R]N1CCNC(C(=O)O)C1C(=O)O</smiles>

$\frac{\text { R Constituent }}{\mathrm{H}-} \quad \frac{\text { Antagonist Compound }}{\text { PzDA }}$

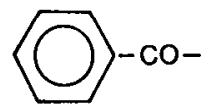

B-PzDA<smiles>COC(=O)c1ccccc1Cl</smiles>

OCB-PzDA<smiles>COc1cccc(Cl)c1</smiles>

$m \mathrm{CB}-\mathrm{PzDA}$<smiles>CC(=O)c1ccc(Cl)cc1</smiles>

$p \mathrm{CB}-\mathrm{PzDA}$

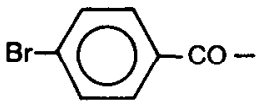

PBB-PZDA

Figure 1. Structures of derivatives of piperazine-2,3-dicarboxylate. $P z D A=$ Piperazine-2,3-dicarboxylate; $B-P z D A, N$-benzoyl-piperazine2,3-dicarboxylate; oCB-PzDA $=N$-(o-chlorobenzoyl)piperazine-2,3dicarboxylate; $\mathrm{m} C B-P z D A, N$-( $m$-chlorobenzoyl)piperazine-2,3-dicarboxylate; $\mathrm{p} C B-P z D A, N$-( $p$-chlorobenzoyl)piperazine-2,3-dicarboxylate; $\mathrm{p} B B-P z D A, N$-( $p$-bromobenzoyl)piperazine-2,3-dicarboxylate.

The most potent antagonists of Schaffer responses tested were $N$-(p-chlorobenzoyl)piperazine-2,3-dicarboxylate ( $p$ CB-PzDA) and $N$-( $p$-bromobenzoyl)piperazine-2,3-dicarboxylate ( $p \mathrm{BB}$ PzDA). These antagonists applied at $200 \mu \mathrm{M}$ depressed Schaffer responses by $51 \pm 5 \%(n=6)$ and $48 \pm 2 \%(n=4)$, respectively (Figs. 2, 3). The $K_{d} s$ calculated for these compounds treated as simple competitive antagonists (Koerner and Cotman, 1982) were $203 \mu \mathrm{M}$ for $p$ CB-PzDA and $197 \mu \mathrm{M}$ for $p$ BB-PzDA. The $K_{\mathrm{d}}$ values calculated for these and the other PzDA derivatives against the Schaffer response were useful for comparing the relative potency of these compounds as synaptic antagonists. $K_{\mathrm{d}}$ values for the other PzDA derivatives were as follows: PzDA, $6700 \mu \mathrm{M} ; o \mathrm{CB}-\mathrm{PzDA}, 1660 \mu \mathrm{M} ; m \mathrm{CB}-\mathrm{PzDA}, 550 \mu \mathrm{M}$; and B-PzDA, $420 \mu \mathrm{M}$.

\section{Antagonism of other hippocampal pathways}

The two most potent Schaffer response antagonists, $p \mathrm{CB}-\mathrm{PzDA}$ and $p \mathrm{BB}-\mathrm{PzDA}$, were also tested at concentrations from 10 to 


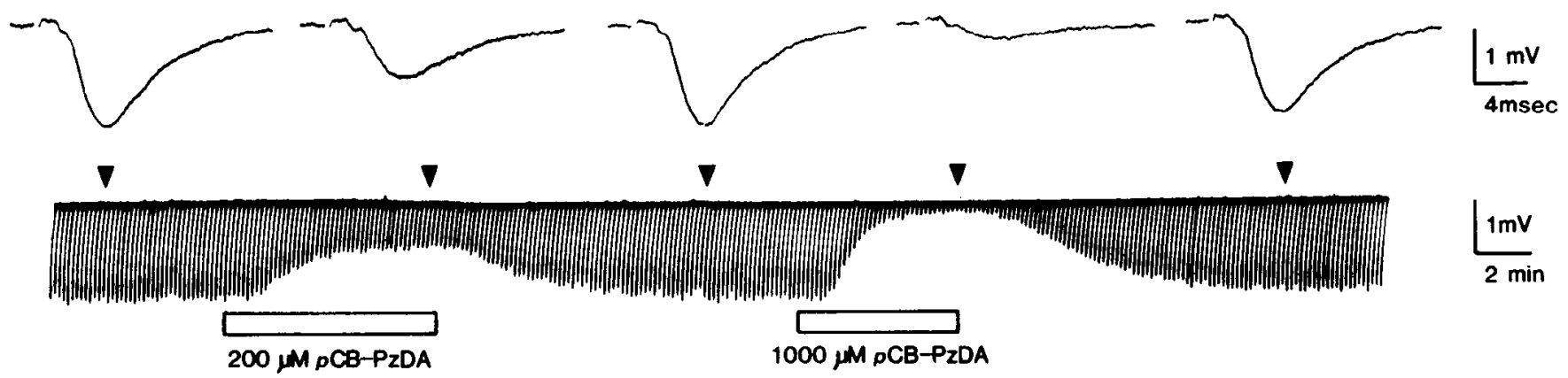

Figure 2. Depression of Schaffer collateral-commissural synaptic field potentials by $p$ CB-PzDA. The lower portion shows the amplitude of the peak negativity of the synaptic field potential. The waveforms in the upper portion are taken at the points indicated by arrowheads. Solutions of $p C B-P z D A$ were introduced into the recording chamber during the intervals indicated by open bars. The waveforms are photographs of oscilloscope traces of individual synaptic potentials.

$1000 \mu \mathrm{M}$ as antagonists in other excitatory hippocampal pathways. These two compounds exhibited similar effects on mossy fiber, lateral perforant path, and medial perforant path responses as on Schaffer synaptic field responses (Fig. 4).

Mossy fiber and perforant path responses were inhibited in the range of $50-80 \%$ by $200 \mu \mathrm{M}$ solutions of $p \mathrm{CB}-\mathrm{PzDA}$ and $p \mathrm{BB}-\mathrm{PzDA}$. The dose dependence of antagonism of mossy fiber and perforant path responses to these compounds is shown in Figure 5; these dose-response relationships can be compared to those for Schaffer responses shown in Figure 3. The effects of $p C B-P z D A$ and $p \mathrm{BB}-\mathrm{PzDA}$ on the four different hippocampal excitatory pathways tested were similar in terms of the time course and reversibility of inhibition and the percent depression of these responses by $10-1000 \mu \mathrm{M}$ solutions of these antagonists. The slightly greater effect of $p C B-P z D A$ and $p \mathrm{BB}-\mathrm{PzDA}$ on mossy fiber responses compared to Schaffer and perforant path responses may have been due to partial contamination of the mossy fiber response by a population spike (Ault and Nadler, 1982).

\section{Antagonism of intracellularly recorded EPSPS}

Intracellularly recorded EPSPs were antagonized by $p$ BB-PzDA and $p$ CB-PzDA. Figure $6 A$ shows the inhibition of the Schaffer collateral-commissural EPSP by $1000 \mu \mathrm{M} p \mathrm{BB}-\mathrm{PzDA}$. Intracellularly recorded Schaffer EPSPs were antagonized $90 \pm 2 \%$ $(n=2)$ by $1000 \mu \mathrm{M} p \mathrm{BB}-\mathrm{PzDA}$ and $48 \pm 5 \%(n=3)$ by 200 $\mu \mathrm{M} p \mathrm{BB}-\mathrm{PzDA}$. Schaffer EPSPs were also blocked by $p$ CB-PzDA. This antagonist blocked the Schaffer EPSP by $88 \pm 6 \%(n=3)$ at $1000 \mu \mathrm{M}$ and by $55 \pm 4 \%(n=3)$ at $200 \mu \mathrm{M}$. The inhibition of Schaffer EPSPs by these antagonists was similar to the inhibition of extracellularly recorded field potentials in terms of time course, reversibility, and potency (cf. Fig. $3 A$ ). Subthreshold EPSPs elicited by low-intensity stimulation and suprathreshold EPSPs that reached firing threshold for action potentials were blocked equally by $p$ BB-PzDA and $p C B-P z D A$.

\section{Lack of antagonism of Schaffer EPSPS by NMDA antagonists} In contrast to the antagonism by PzDA analogs of Schaffer synaptic responses, specific NMDA antagonists did not block Schaffer responses (Fig. 7). Intracellularly recorded Schaffer EPSPs were blocked by less than $10 \%$ by $50 \mu \mathrm{M}$ D-2-amino-5phosphonopentanoate (D-AP5) or $100 \mu \mathrm{M}$ D,L-2-amino-7-phosphonoheptanoate (DL-AP7). These specific concentrations of these antagonists block NMDA responses by over $90 \%$ without blocking kainate or quisqualate responses in the hippocampus (Hablitz and Langmoen, 1984; Harris et al., 1984) and other CNS structures (Davies et al., 1982; Evans et al., 1982). Subthreshold Schaffer EPSPs (mean amplitude, $2.2 \pm 0.3 \mathrm{mV}$; $n=6$ ) were blocked $5 \pm 11 \%$, and action potentials elicited by suprathreshold orthodromic stimulation were not blocked by $50 \mu \mathrm{M}$ D-AP5 (Fig. 7A). Similarly, subthreshold EPSPs $(2.0 \pm$ $0.3 \mathrm{mV} ; n=4$ ) were blocked less than $10 \%$, and EPSPs that

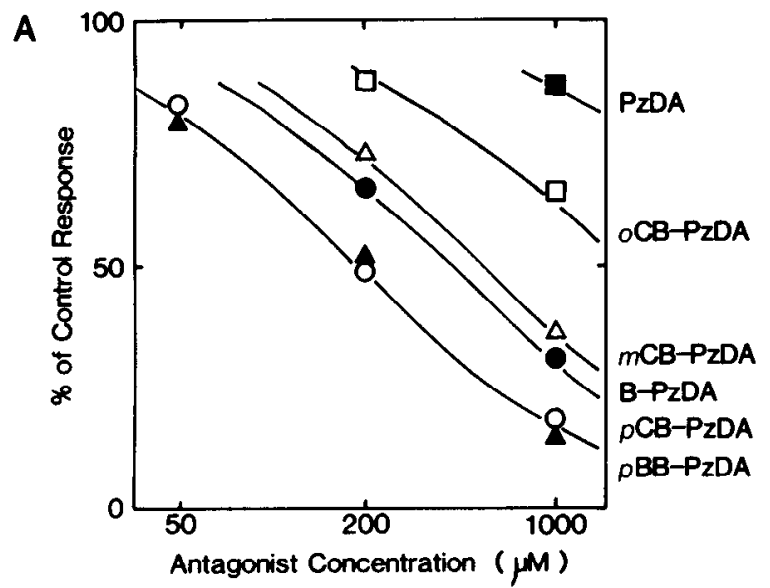

$\mathbf{B}$

Control

PzDA

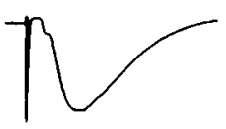

OCB-PZDA
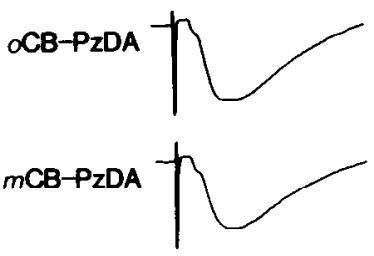

$1000 \mu \mathrm{M}$ Antagonist
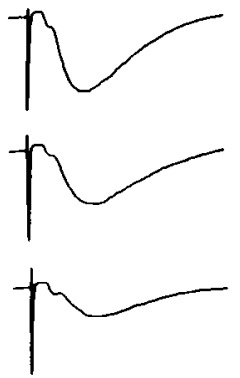
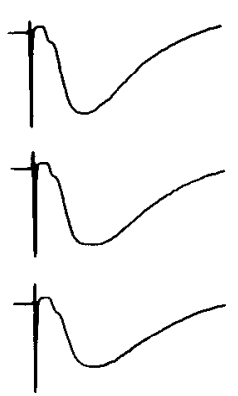

$1 \mathrm{mV}$

$4 \mathrm{msec}$

Figure 3. Inhibition of Schaffer collateral-commissural synaptic field potentials by PzDA derivatives. $A$, Dose-response curves for the inhibition of Schaffer responses. Ordinate, The amplitude of field potentials in antagonist solution compared to control responses. Each point represents the mean of data from at least four slices. Error bars were omitted for clarity; maximum SEM, $\pm 6 \%$. Solid lines, The theoretical curves of inhibition by a simple antagonist with a Hill coefficient of 1 and $K_{\mathrm{d}}$ values as listed in the text. $B$, Examples of Schaffer collateral-commissural synaptic field potentials inhibited by PzDA derivatives. Waveforms are averages of six stimulations. Antagonist solutions were superfused for 6-10 min, followed by superfusion with control medium for 15 min. Abbreviations are as in Figure 1. 
Control $\quad 1000 \mu \mathrm{M} p \mathrm{BB}-\mathrm{PzDA}$

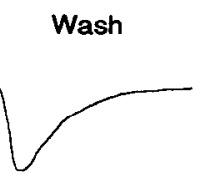

B LPP
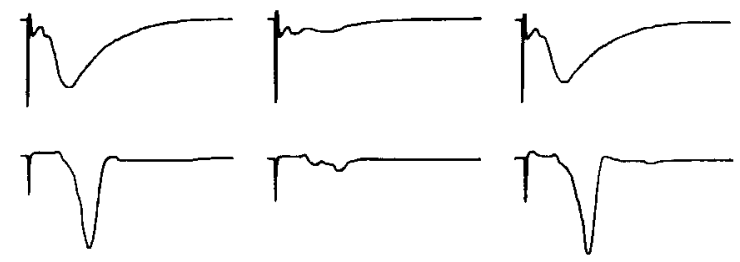

C MF
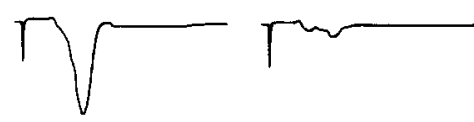

$\frac{1 \mathrm{mv}}{4 \mathrm{msec}}$

Figure 4. Depression of hippocampal synaptic field potentials by $p$ BBPzDA. Waveforms are averages of six stimulations from the indicated hippocampal pathways. Submerged slices were exposed to $1000 \mu \mathrm{M}$ antagonist solutions for 6-10 min, followed by a $15 \mathrm{~min}$ wash with control medium. $A$, Medial perforant path $(M P P)$ response; $B$, lateral perforant path $(L P P)$ response; $C$, mossy fiber $(M F)$ response.

reached firing threshold were not blocked by applications of 100 $\mu \mathrm{M}$ DL-AP7 (Fig. 7B). Application of the L-isomer of AP5 to two CA1 neurons also blocked sub- and suprathreshold EPSPs less than $10 \%$.

\section{Lack of excitatory effects}

None of the PzDA derivatives we tested (Fig. 3) showed signs of excitatory activity toward hippocampal neurons. When applied as 10-1000 $\mu \mathrm{M}$ solutions, these compounds depressed synaptic field potentials without exhibiting extracellular signs of agonist activity such as appearance of a population spike or an abnormally steep dose-response curve at higher drug concentrations (Koerner and Cotman, 1982). In addition, we recorded extracellular DC potentials in CA1 stratum radiatum during applications of $10 \mathrm{~mm}$ droplets of several acidic amino acids, including the PzDA derivatives described above. Application of L-glutamate produced extracellular depolarizations of 2-6 $\mathrm{mV}$ (Lanthorn and Cotman, 1983). As described by others (Collingridge et al., 1983a; Crunelli et al., 1983; Koerner and Cotman, 1982), cis-2,3-piperidine dicarboxylate produced excitatory responses with focal depolarizations up to $10 \mathrm{mV}$ and also elicited epileptiform-like bursting activity in some slices. The PzDA derivatives listed in Figure 1, applied as $10 \mathrm{~mm}$ droplets, did not elicit excitatory responses in the form of DC depolarizations or neuronal firing. The largest focal depolarizations elicited by PzDA derivatives were less than $0.5 \mathrm{mV}$.

A more direct examination of nonspecific effects of PzDA derivatives was made during intracellular recordings from $\mathrm{CA} 1$ pyramidal neurons. Application of 200 and $1000 \mu \mathrm{M} p$ CB-PzDA and $p \mathrm{BB}-\mathrm{PzDA}$ never affected resting membrane potential, action potential amplitude, or input resistance in the eight CA1 pyramidal neurons to which these antagonists were applied (Fig. $6 B)$.

\section{Antagonism of excitant amino acid responses}

The ability of PzDA derivatives to antagonize responses produced by amino acid excitants was examined by applying quisqualate, kainate, and NMDA to CA1 stratum radiatum using multibarrel iontophoretic pipettes. The effects of applications of $1000 \mu \mathrm{M}$ solutions of PzDA derivatives on extracellular focal depolarizations produced by these excitants are shown in Figure 8. The antagonism of excitant amino acid responses by PzDA derivatives is summarized and compared to antagonism of Schaffer collateral-commissural synaptic responses in Figure 9.
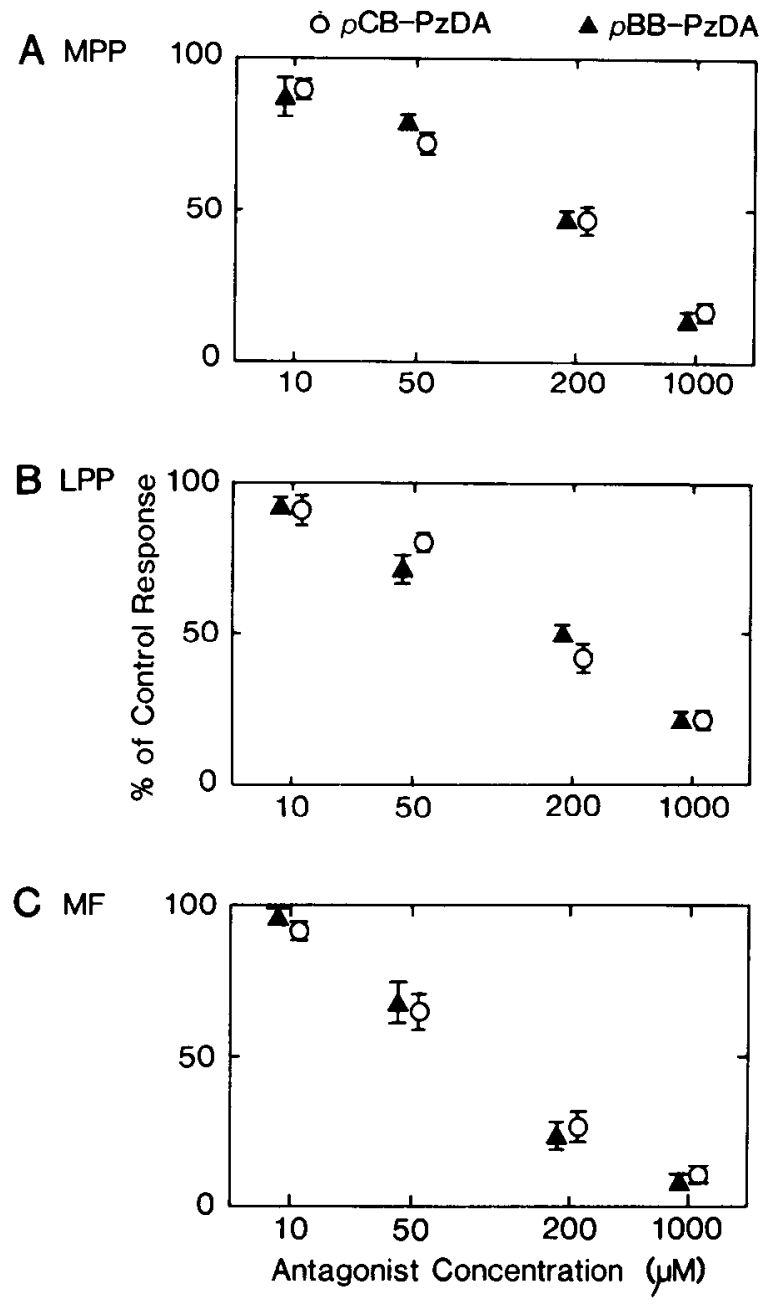

Figure 5. Inhibition of hippocampal synaptic field potentials by $p \mathrm{CB}-$ PzDA $(\Lambda)$ and $p$ BB-PzDA (O). Ordinates, Amplitudes of field potentials in antagonist solutions compared to control response. Each point represents the mean and SEM for data from at least four slices. $A$, MPP; $B$, LPP; $C$, MF pathway (see Fig. 4).

Each of the PzDA derivatives we tested depressed NMDA responses to a greater extent than kainate or quisqualate responses. Several of these derivatives - including PzDA, $m C B-P z D A$, and $p \mathrm{CB}-\mathrm{PzDA}$ - were quite potent as NMDA blockers; these antagonists blocked NMDA focal depolarizations by $80-90 \%$ (Fig. 9).

The order of potency of the PzDA derivatives shown in Figure 9 against kainate responses exactly matches their order of potency against Schaffer synaptic responses, although the PzDA derivatives were less potent against kainate-induced responses compared to Schaffer synaptic responses, with the exception of PzDA. Depression of kainate responses by $1000 \mu \mathrm{M}$ antagonist solutions ranged from $23 \pm 3 \%(n=4)$ for PzDA to $66 \pm 6 \%$ $(n=4)$ for $p$ CB-PzDA.

The inhibition by $\mathrm{PzDA}$ derivatives of quisqualate responses was similar to that of kainate and the Schaffer synaptic response, although quisqualate-induced responses were depressed less by PzDA derivatives than NMDA or kainate responses (Fig. 9). Inhibition of quisqualate responses by $1000 \mu \mathrm{M}$ antagonist solutions ranged from 5 to $30 \%$.

\section{Discussion}

The PzDA derivatives, particularly $p C B-P z D A$ and $p B B-P z D A$, must be considered as important new antagonists of excitatory 


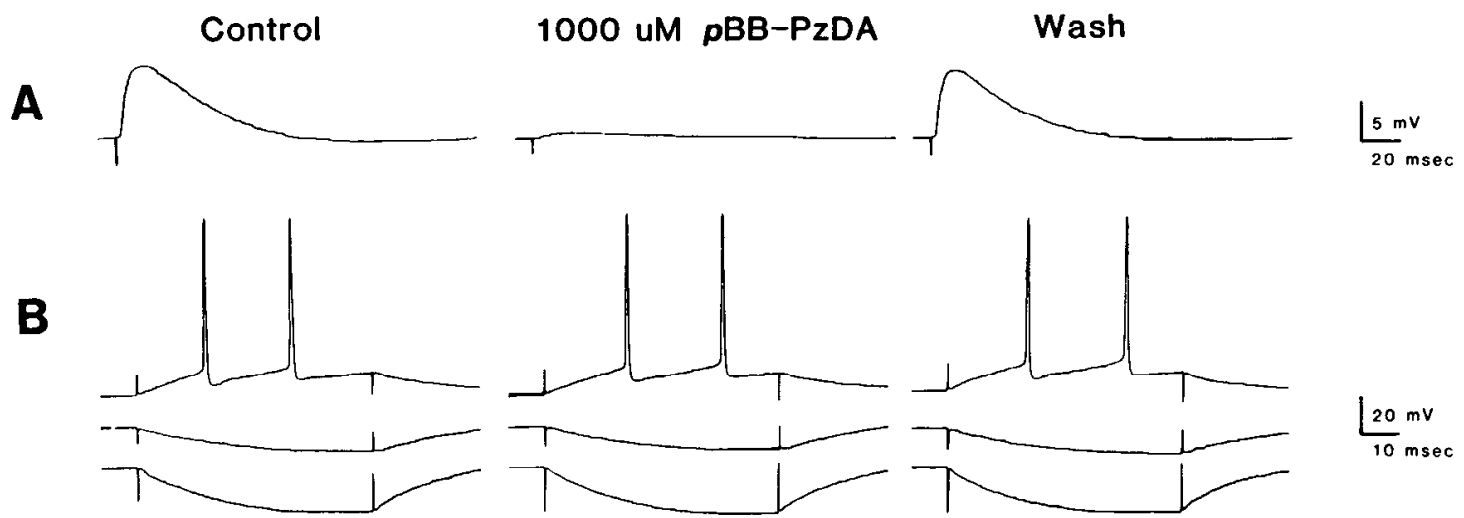

Figure 6. Effects of $p \mathrm{BB}-\mathrm{PzDA}$ on intracellularly recorded Schaffer collateral-commissural EPSPs and membrane properties. $A$, Inhibition of Schaffer EPSP by $1000 \mu \mathrm{M} p$ BB-PzDA. Waveforms are averages of 20 stimulations. $B$, Lack of effect on action potential amplitude and input resistance by $1000 \mu \mathrm{m} p \mathrm{BB}-\mathrm{PzDA}$. The cell was injected with $-0.5,-0.25$, and $+0.3 \mathrm{nA}$ current to elicit these responses. The submerged slice was exposed to the antagonist solution for $10 \mathrm{~min}$ followed by a $20 \mathrm{~min}$ wash with control medium. The medium contained $10 \mu \mathrm{M}$ picrotoxin and elevated $\mathrm{Ca}^{2+}$ and $\mathrm{Mg}^{2+}$ (see Materials and Methods).

neurotransmission in the hippocampus and other CNS structures. These PzDA derivatives are the most potent acidic amino acid antagonists yet described for the Schaffer collateral-commissural pathway. The $p$ CB-PzDA and $p$ BB-PzDA derivatives inhibit Schaffer collateral-commissural EPSPs by $50 \%$ at 200 $\mu \mathrm{M}$; these compounds are significantly more potent than previously available amino acid antagonists such as kynurenate, $\gamma$-D-glutamylglycine, and cis-2,3-piperidine dicarboxylate (Collingridge et al., 1983b; Ganong et al., 1983b; Koerner and Cotman, 1982; Robinson et al., 1984). The depressant action of this series of compounds against the Schaffer synaptic response

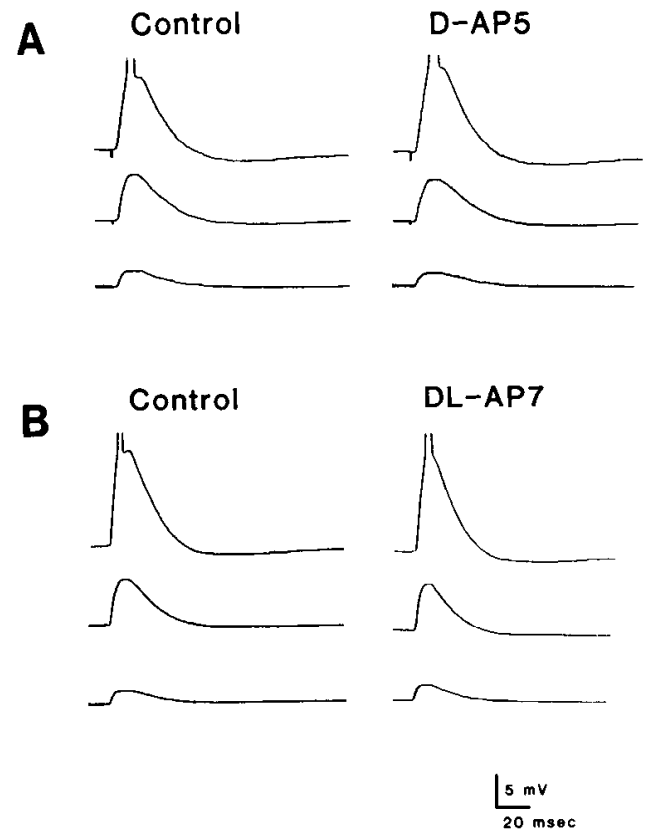

Figure 7. Specific NMDA antagonists do not inhibit Schaffer collateral-commissural EPSPs. Three different stimulus intensities were used to produce two subthreshold and one suprathreshold intracellularly recorded Schaffer EPSP. $A$, Schaffer EPSPs in $50 \mu \mathrm{M}$ D-AP5 compared to control medium. $B$. Schaffer EPSPs in $100 \mu \mathrm{M}$ DL-AP7 compared to control medium. Waveforms are averages of three to six responses. Action potentials in suprathreshold responses are truncated. Submerged slices were exposed to antagonist solutions for at least $10 \mathrm{~min}$. The medium contained $10 \mu \mathrm{M}$ picrotoxin and elevated $\mathrm{Ca}^{2+}$ and $\mathrm{Mg}^{2+}$ (see Materials and Methods). is similar to the inhibition of dorsal root monosynaptic excitation in the spinal cord (Davies et al., 1984). Thus, $p$ CB-PzDA and $p$ BB-PzDA are the most potent synaptic antagonists of this series against hippocampal and spinal cord monosynaptic responses, while $m C B-P z D A, ~ o C B-P z D A$, and PzDA are, in descending order, less potent.

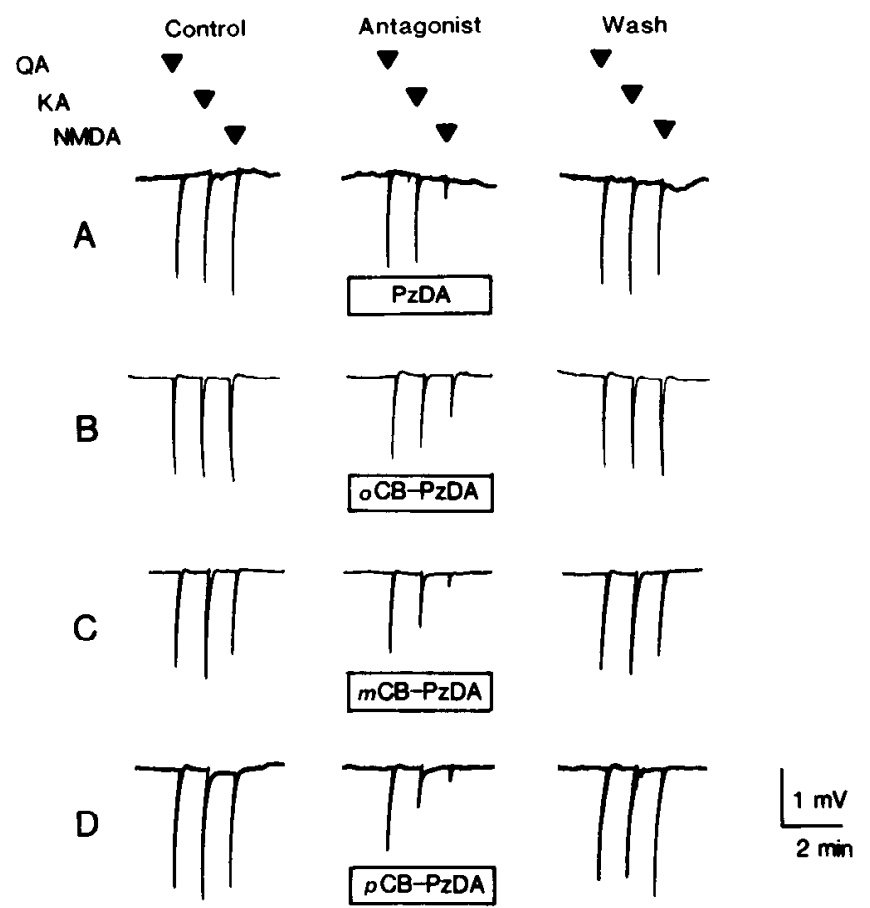

Figure 8. Effects of derivatives of PzDA on excitatory amino acidinduced responses in CAl stratum radiatum. Waveforms are continuous DC records from a chart recorder. Gaps represent intervals of 10-20 min. Slices were completely submerged in medium containing $1 \mu \mathrm{M}$ tetrodotoxin. Bars, The presence of antagonist in the medium in which the slices were submerged. Quisqualate $(Q A)$, kainate $(K A)$, or $N$-methyl-D-aspartate $(N M D A)$ were applied iontophoretically at the times marked. $A$, Effects of $1000 \mu \mathrm{M}$ PzDA on responses induced by QA ( 2 sec, $15 \mathrm{nA}), \mathrm{KA}(2 \mathrm{sec}, 30 \mathrm{nA})$, and NMDA (2 sec, $25 \mathrm{nA}) . B$, Effects of $1000 \mu \mathrm{M} O \mathrm{CB}-\mathrm{PzDA}$ on responses induced by QA $(2 \mathrm{sec}, 12 \mathrm{nA}), \mathrm{KA}$ $(2 \mathrm{sec}, 30 \mathrm{nA}$ ), and NMDA (5 sec, $25 \mathrm{nA})$. C, Effects of $1000 \mu \mathrm{M} m \mathrm{CB}-$ PzDA on responses induced by QA $(2 \mathrm{sec}, 15 \mathrm{nA}), \mathrm{KA}(2 \mathrm{sec}, 40 \mathrm{nA})$, and NMDA (2 sec, $25 \mathrm{nA})$. $D$, Effects of $1000 \mu \mathrm{M} p \mathrm{CB}-\mathrm{PzDA}$ on responses induced by QA ( $2 \mathrm{sec}, 10 \mathrm{nA}), \mathrm{KA}(2 \mathrm{sec}, 35 \mathrm{nA})$, and NMDA (2 sec, $30 \mathrm{nA})$. 


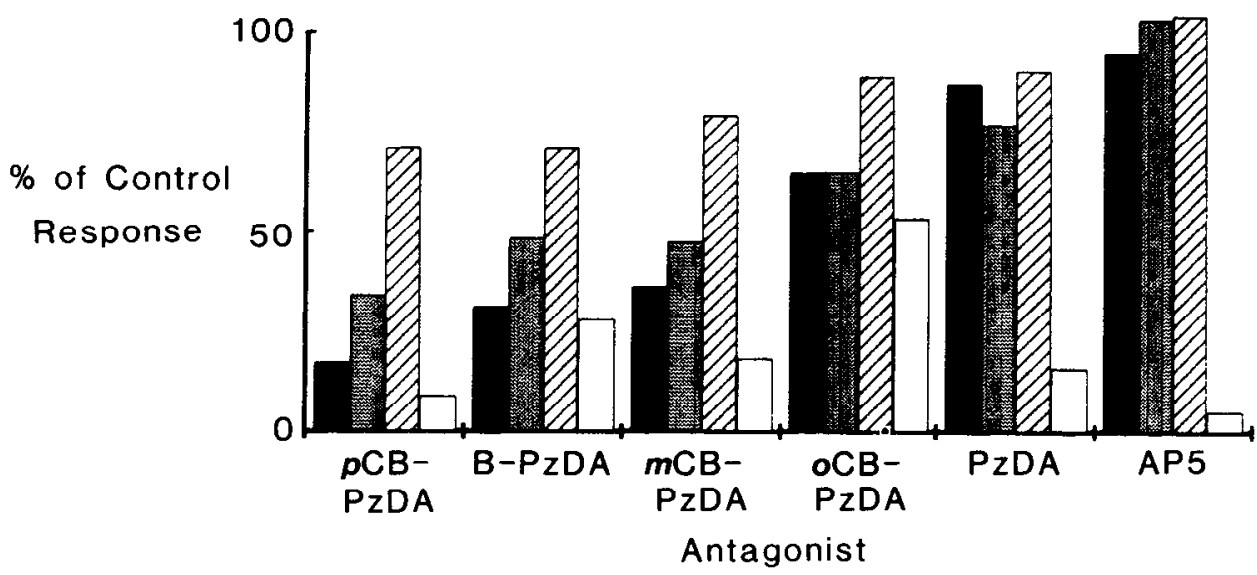

Figure 9. Effects of derivatives of PzDA on excitatory amino acid-induced depolarizations and synaptic responses in CA1 stratum radiatum. Ordinate is amplitude of responses elicited by electrical stimulation (synaptic, black), kainate (gray), quisqualate (cross-hatched), and NMDA (open) in antagonist solutions, as compared to control responses. PzDA derivatives were applied as $1000 \mu \mathrm{M}$ solutions. DLAP5 $(100 \mu \mathrm{M})$ data taken from Harris et al. (1984). Each point represents the mean data from at least four slices. SEMs ranged from \pm 1 to $\pm 6 \%$. Excitatory amino acid responses were recorded from slices submerged in medium containing $1 \mu \mathrm{M}$ TTX. For abbreviations of compounds, see Figure 1 .
The mechanism of action of these compounds is likely to be antagonism of the postsynaptic receptors that mediate synaptic transmission. Although we did not test effects on amino acid uptake or presynaptic release, the ability of PzDA analogs to block excitant amino acid-induced responses indicates that these antagonists act on postsynaptic receptors. Consistent with this notion is the observation that $p C B-P z D A$ interacts with pairedpulse stimulation of the medial perforant path in a manner expected of a postsynaptic antagonist (Harris and Cotman, 1985). In addition, $p \mathrm{BB}-\mathrm{PzDA}$ causes a reduction in amplitude of spontaneous miniature EPSPs at the guinea pig mossy fiber-CA3 pyramidal neuron synapse, indicative of a postsynaptic action without showing nonspecific membrane effects (Ganong et al., 1985). The PzDA series of analogs do not show the depolarizing actions toward hippocampal neurons that have been described for cis-2,3-piperidine dicarboxylate.

The major postsynaptic receptor type that mediates excitatory neurotransmission in the Schaffer pathway is not of the NMDA class. The lack of effect of the specific NMDA antagonists D-AP5 and DL-AP7 on intracellularly recorded Schaffer EPSPs (Fig. 7) confirms observations from extracellular recording in this pathway (Collingridge et al., 1983b; Harris et al., 1984; Koerner and Cotman, 1982). However, NMDA receptors may play a role in some aspect of synaptic transmission in this pathway, since Schaffer responses are affected by NMDA antagonists under certain conditions (Coan and Collingridge, 1985; Hablitz and Langmoen, 1984), and long-term potentiation of the Schaffer synaptic response is blocked by NMDA antagonists (Collingridge et al., 1983b; Harris et al., 1984; Wigstrom and Gustafson, 1984).

In addition to their effect on Schaffer responses, $p C B-P z D A$ and $p \mathrm{BB}-\mathrm{PzDA}$ antagonize excitatory synaptic responses in the medial and lateral perforant path and the mossy fiber path. Excitatory responses in these pathways were inhibited in the range of $50-80 \%$ by $200 \mu \mathrm{M}$ solutions of these antagonists. The ability of these antagonists to block synaptic transmission in these pathways indicates the presence of a similar or identical postsynaptic receptor in these different pathways. In accordance with this view are the observations that there are similarities in the abilities of other acidic amino acid antagonists to depress the different hippocampal pathways (Collingridge et al., 1983b; Ciunelli et al., 1982, 1983; Ganong et al., 1983a, b; Koerner and Cotman, 1982; Lanthorn et al., 1984; Robinson et al., 1983). However, the lateral perforant path may have an additional receptor present, since $\mathrm{L}-2$-amino-4-phosphonobutyrate is a potent antagonist of this pathway but not of the Schaffer collateralcommissural pathway (Collingridge et al., 1983b; Koerner and Cotman, 1981, 1982).
The PzDA derivatives we tested were more potent against NMDA-induced responses than kainate or quisqualate-induced responses in the hippocampus. The order of potency of PzDA derivatives against NMDA, kainate, and quisqualate responses is similar to the effects of $\gamma$-D-glutamylglycine (Collingridge et al., 1983a; Crunelli et al., 1983; Davies and Watkins, 1983; Watkins et al., 1981) and kynurenate (Cochran, 1983; Ganong et al., 1983a, b; Perkins and Stone, 1984). These antagonists are also more potent against NMDA responses than against kainate or quisqualate responses and block hippocampal excitatory transmission (Collingridge et al., 1983b; Ganong et al., 1983b; Koerner and Cotman, 1982; Perkins and Stone, 1984; Robinson et al., 1983). Amino acid-induced excitations in the spinal cord are also depressed by PzDA analogs, but in this region, quisqualate and kainate responses are more sensitive than NMDA responses to depression by PzDA derivatives (Davies et al., 1984). The greater potency of PzDA derivatives against NMDA responses in the hippocampus may be due to differences in $\mathrm{Mg}^{2+}$ concentration used in the present study compared to the study of Davies et al. (1984). NMDA-induced responses in neurons from several CNS structures are sensitive to changes in $\mathrm{Mg}^{2+}$ concentration (Ault et al., 1980; Crunelli and Mayer, 1984; Dingledine, 1983; Nowak et al., 1984). The difference in relative potency of the PzDA analogs against NMDA and kainate or quisqualate in the spinal cord compared to hippocampus could also be due to the existence of NMDA receptor subtypes in these regions (McLennan, 1984; Perkins and Stone, 1983).

The antagonism of Schaffer synaptic responses by PzDA derivatives closely resembles the antagonism of kainate responses by these compounds. The antagonism of quisqualate responses by $\mathrm{PzDA}$ derivatives shows a similar rank order of potency as kainate responses, although quisqualate responses are less sensitive to these antagonists. The similar rank order of potency of the PzDA series against kainate and quisqualate responses (Fig. 9) is probably due to the similarities in these receptor types, as shown by their interaction with a variety of ligands (Foster and Fagg, 1984). The greater potency of hippocampal synaptic antagonists toward kainate, rather than quisqualate, receptors may indicate that synaptic receptors are more similar to the kainate type. Kainate binding sites have been shown to be enriched in synaptic junction membranes (Foster et al., 1981), although it is unlikely that kainate receptors are restricted to a synaptic location, since extrasynaptic kainate receptors have been demonstrated in the hippocampus (Fagni et al., 1983) and spinal cord (Davies et al., 1979). The range of potencies of this new series of antagonists will be useful for further structureactivity analyses of ligands for synaptic receptors.

The relative potencies of derivatives of $\mathrm{PzDA}$ against synaptic 
and amino acid-induced excitations support a role for kainate (or quisqualate) postsynaptic receptors in excitatory neurotransmission in the hippocampus. The endogenous ligand for synaptic receptors remains unknown, although a great deal of biochemical evidence suggests that L-glutamate is a hippocampal excitatory transmitter (Cotman and Nadler, 1981; Fagg and Foster, 1983; Fonnum, 1984; Storm-Mathisen, 1977). The high affinity of L-glutamate toward kainate and quisqualate receptors (Foster and Fagg, 1984; McLennan, 1983; Watkins and Evans, 1981 ) is consistent with the notion that one of these receptor types could mediate postsynaptic actions of naturally released L-glutamate in the hippocampus.

\section{References}

Ault, B., and J. V. Nadler (1982) Baclofen selectively inhibits transmission at synapses made by axons of CA3 pyramidal cells in the hippocampal slice. J. Pharmacol. Exp. Ther. 223: 291-297.

Ault, B., R. H. Evans, A. A. Francis, D. J. Oakes, and J. C. Watkins (1980) Selective depression of excitatory amino acid induced depolarizations by magnesium ions in isolated spinal cord preparations. J. Physiol. (Lond.) 307: 413-428.

Brown, T. H., and D. Johnston (1983) Voltage-clamp analysis of mossy fiber synaptic input to hippocampal neurons. J. Neurophysiol. 50: 487-507.

Coan, E. J., and G. L. Collingridge (1985) Magnesium ions block an $\mathrm{N}$-methyl-D-aspartate receptor-mediated component of synaptic transmission in rat hippocampus. Neurosci. Lett. 53: 21-26.

Cochran, S. L. (1983) Pharmacological antagonism of climbing fiber-, parallel fiber-, and acidic amino acid-induced excitation of frog cerebellar Purkinje cells. Soc. Neurosci. Abstr. 9: 1142.

Collingridge, G. L., S. J. Kehl, and H. McLennan (1983a) The antagonism of amino acid-induced excitations of rat hippocampal CA1 neurones in vitro. J. Physiol. (Lond.) 334: 19-31.

Collingridge, G. L., S. J. Kehl, and H. McLennan (1983b) Excitatory amino acids in synaptic transmission in the Schaffer collateral-commissural pathway of the rat hippocampus. J. Physiol. (Lond.) 334: 33-46.

Cotman, C. W., and J. V. Nadler (1981) Glutamate and aspartate as hippocampal transmitters: Biochemical and pharmacological evidence. In Glutamate: Transmitter in the Central Nervous System, P. J. Roberts, J. Storm-Mathisen, and G. A. R. Johnston, eds., pp. 117154, Wiley, Chichester, UK.

Crunelli, V., and M. L. Mayer (1984) Membrane resistance changes accompanying the response to NMDA in slices prepared from rat hippocampus. J. Physiol. (Lond.) 353: 97P.

Crunelli, V., S. Forda, G. L. Collingridge, and J. S. Kelly (1982) Intracellular recorded synaptic antagonism in the rat dentate gyrus. Nature 300: 450-452.

Crunelli, V., S. Forda, and J. S. Kelly (1983) Blockade of amino acidinduced depolarizations and inhibition of excitatory post-synaptic potentials in rat dentate gyrus. J. Physiol. (Lond.) 341: 627-640.

Davies, J., and J. C. Watkins (1982) Actions of $D$ and $L$ forms of 2-amino-5-phosphonovalerate and 2-amino-4-phosphonobutyrate in the cat spinal cord. Brain Res. 235: 378-386.

Davies, J., and J. C. Watkins (1983) Role of excitatory amino acid receptors in mono- and polysynaptic excitation in the cat spinal cord. Exp. Brain Res. 49: 280-290.

Davies, J., R. H. Evans, A. A. Francis, and J. C. Watkins (1979) Excitatory amino acid receptors and synaptic excitation in the mammalian central nervous system. J. Physiol. (Paris) 75: 641-644.

Davies, J., R. H. Evans, A. W. Jones, D. A. S. Smith, and J. C. Watkins (1982) Differential activation and blockade of excitatory amino acid receptors in the mammalian and amphibian central nervous systems. Comp. Biochem. Physiol. 72C: 211-224.

Davies, J., A. W. Jones, M. J. Sheardown, D. A. S. Smith, and J. C. Watkins (1984) Phosphono dipeptides and piperazine derivatives as antagonists of amino acid-induced and synaptic excitation in mammalian and amphibian spinal cord. Neurosci. Lett. 52: 79-84.

Dingledine, R. (1983) N-methyl-aspartate activates voltage dependent calcium conductance in rat hippocampal pyramidal cells. J. Physiol. (Lond.) 343: 385-405.

Evans, R. H., A. A. Francis, K. Hunt, D. J. Oakes, and J. C. Watkins (1979) Antagonism of excitatory amino acid-induced responses and of synaptic excitation in the isolated spinal cord of the frog. $\mathrm{Br}$. J. Pharmacol. 67: 591-603.

Evans, R. H., A. A. Francis, A. W. Jones, D. A. S. Smith, and J. C Watkins (1982) The effects of a series of $\omega$-phosphonic $\alpha$-carboxylic amino acids on electrically evoked and excitant amino acid-induced responses in isolated spinal cord preparations. $\mathrm{Br}$. J. Pharmacol. 75 . 65-75.

Fagg, G. E., and A. C. Foster (1983) Amino acid neurotransmitters and their pathways in the mammalian central nervous system. Neuroscience 9: 701-719.

Fagni, L., M. Baudry, and G. Lynch (1983) Classification and propcrtics of acidic amino acid receptors in hippocampus. I. Electrophysiological studies of an apparent desensitization and interactions with drugs which block transmission. J. Neurosci. 3: 1538-1546.

Flatman, J. A., and J. D. C. Lambert (1979) Sustained extracellular potentials in the cat spinal cord during the microiontophoretic application of excitatory amino acids. J. Neurosci. Methods 1 : 205218.

Fonnum, F. (1984) Glutamate: A neurotransmitter in mammalian brain. J. Neurochem. 42: 1-11.

Foster, A. C., and G. E. Fagg (1984) Acidic amino acid binding sites in mammalian neuronal membranes: Their characteristics and relationship to synaptic receptors. Brain Res. Rev. 7: 103-164.

Foster, A. C., E. E. Mena, D. T. Monaghan, and C. W. Cotman (1981) Synaptic localization of kainic acid binding sites. Nature $289: 73-75$.

Ganong, A. H., and C. W. Cotman (1982) Acidic amino acid antagonists of lateral perforant path synaptic transmission: Agonist-antagonist interactions in the dentate gyrus. Neurosci. Lett. 34: 195200.

Ganong, A. H., T. H. Lanthorn, and C. W. Cotman (1983a) Agonist and antagonist actions of kynurenic and quinolinic acid in rat hippocampal slices. Soc. Neurosci. Abstr. 9: 1187.

Ganong, A. H., T. H. Lanthorn, and C. W. Cotman (1983b) Kynurenic acid inhibits synaptic and acidic amino acid-induced responses in the rat hippocampus and spinal cord. Brain Res. 273: 170-174.

Ganong, A. H., C. W. Cotman, A. W. Jones, and J. C. Watkins (1984) Analogues of piperazine-2,3-dicarboxylic acid inhibit excitatory synaptic transmission in rat hippocampal slices. Soc. Neurosci. Abstr. 10: 228 .

Ganong, A. H., M. N. Perkins, J. A. Flatman, and C. W. Cotman (1985) L-2-Amino-4-phosphonobutyrate acts presynaptically to block neurotransmission in the hippocampus. Soc. Neurosci. Abstr. 11: 1003.

Hablitz, J. J., and I. A. Langmoen (1984) Possible NMDA receptor mediation of synaptic transmission in the hippocampal CA1 region. Soc. Neurosci. Abstr. 10: 415.

Harris, E. W., and C. W. Cotman (1985) Effects of synaptic antagonists on perforant path paired-pulse plasticity: Differentiation of pre- and post-synaptic antagonism. Brain Res. 334: 348-353.

Harris, E. W., A. H. Ganong, and C. W. Cotman (1984) Long-term potentiation in the hippocampus involves activation of N-methyl-Daspartate receptors. Brain Res. 323: 132-137.

Koerner, J. F., and C. W. Cotman (1981) Micromolar L-2-amino-4phosphonobutyric acid selectively inhibits perforant path synapses from lateral entorhinal cortex. Brain Res. 216: 192-198.

Koerner, J. F., and C. W. Cotman (1982) Response of Schaffer collateral-CA 1 pyramidal cell synapses of the hippocampus to analogues of acidic amino acids. Brain Res. 251: 105-115.

Koerner, J. F., and C. W. Cotman (1983) A microperfusion chamber for brain slice pharmacology. J. Neurosci. Methods 7: 243-251.

Lanthorn, T. H., and C. W. Cotman (1981) Baclofen selectively inhibits excitatory synaptic transmission in the hippocampus. Brain Res. 225: 171-178.

Lanthorn, T. H., and C. W. Cotman (1983) Relative potency of analogues of excitatory amino acids on hippocampal CA1 neurons. Neuropharmacology 22: 1343-1348.

Lanthorn, T. H., A. H. Ganong, and C. W. Cotman (1984) 2-Amino4-phosphonobutyrate selectively blocks mossy fiber-CA3 responses in guinea pig but not rat hippocampus. Brain Res. 290: 174-178.

McLennan, H. (1983) Receptors for the excitatory amino acids in the mammalian central nervous system. Progr. Neurobiol. 20: 251-271.

McLennan, H. (1984) A comparison of the effects of N-methyl-Daspartate and quinolinate on central neurons in the rat. Neurosci. Lett. 46: 157-160.

McNaughton, B. L. (1980) Evidence for two physiologically distinct perforant pathways to the fascia dentata. Brain Res. 204: 1-19. 
Monaghan, D. T., and C. W. Cotman (1985) Distribution of N-Methyl-D-aspartate-sensitive $\mathrm{L}-\left[{ }^{3} \mathrm{H}\right]$ Glutamate-binding sites in rat brain. J. Neurosci. 5: 2909-2919.

Nowak, L. P. Bregestovski, P. Ascher, A. Herbet, and A. Prochiantz (1984) Magnesium gates glutamate-activated channels in mouse central neurones. Nature 307: 462-465.

Perkins, M. N., and T. W. Stone (1983) Quinolinic acid: Regional variations in neuronal sensitivity. Brain Res. 259: 172-176.

Perkins, M. N., and T. W. Stone (1984) A study of kynurenic acid and excitatory amino acids in the rat hippocampus. J. Physiol. (Lond.) 357: $118 \mathrm{P}$.

Robinson, M. B., K. D. Anderson, and J. F. Koerner (1984) Kynurenic acid as an antagonist of hippocampal excitatory transmission. Brain Res. 309: 119-126.

Storm-Mathisen, J. (1977) Localization of transmitter candidates in the brain: The hippocampal formation as a model. Progr. Neurobiol. 8: 119-181.
Thompson, A. M., D. C. West, and D. Lodge (1985) An N-methylaspartate receptor-mediated synapse in rat cerebral cortex: A site of action of ketamine? Nature 313: 479-481.

Watkins, J. C., and R. H. Evans (1981) Excitatory amino acid transmitters. Annu. Rev. Pharmacol. Toxicol. 21: 165-204.

Watkins, J. C., J. Davies, R. H. Evans, A. A. Francis, and A. W. Jones (1981) Pharmacology of receptors for excitatory amino acids. In Glutamate as a Neurotransmitter, G. DiChiara and G. L. Gessa, eds., pp. 263-273, Raven, New York.

White, W. F., J. V. Nadler, and C. W. Cotman (1979) The effect of acidic amino acid antagonists on synaptic transmission in the hippocampal formation in vitro. Brain Res. 164: 177-194.

Wigstrom, H., and B. Gustafson (1984) A possible candidate of the postsynaptic condition for long-lasting potentiation in the guinea pig hippocampus in vitro. Neurosci. Lett. 44: 327-332. 